ISSN = 1980-993X - doi:10.4136/1980-993X
www.ambi-agua.net
E-mail: ambi-agua@agro.unitau.br
Tel.: (12) 3625-4212

\title{
Avaliação de eventos de inundação na Região Norte Fluminense, Rio de Janeiro, utilizando imagens de sensores remotos
}

\author{
(http://dx.doi.org/10.4136/ambi-agua.817) \\ José Carlos Mendonça ${ }^{1}$; Ramon Morais de Freitas ${ }^{2}$; \\ Yosio Edemir Shimabukuro ${ }^{2}$; \\ Valdo da Silva Marques ${ }^{3}$ \\ ${ }^{1}$ Laboratório de Engenharia Agrícola - LEAG/UENF - Campos dos Goytacazes, RJ \\ e-mail: mendonca@uenf.br; \\ ${ }^{2}$ Instituto Nacional de Pesquisas Espaciais - INPE São José dos Campos, SP \\ e-mail: yosio@dsr.inpe.br; ramon@dsr.inpe.br; \\ ${ }^{3}$ Laboratório de Meteorologia - LAMET/UENF-Macaé, RJ \\ e-mail: valdo@lenep.uenf.br
}

\section{RESUMO}

O presente trabalho teve por objetivo identificar e quantificar, por meio de imagens de sensoriamento remoto, as áreas atingidas pelas inundações ocorridas no período do verão de 2008/2009 na região Norte Fluminense, Rio de Janeiro. Para isso, foram utilizadas imagens dos sensores TM Landsat-5 e CCD CBERS-2B adquiridas antes e após a ocorrência das inundações. Nessas imagens foram aplicadas o Modelo Linear de Mistura Espectral - MLME para realçar as áreas ocupadas com os corpos d’água. Concluiu-se que, após comparar a imagem TM do dia 26/07/2007 (sem inundação) com as imagens TM (17/11/2008) e CCD (20/01/2009) tomadas depois do período chuvoso na região, o espelho d’água da região sofreu um incremento de 2,61 vezes, correspondendo a área total de 99.000 ha atingida pelas águas.

Palavras-chave: Sensoriamento remoto; Modelo Linear de Mistura Espectral; recursos hídricos; inundações.

\section{Evaluation of floodings events in the Norte Fluminense, Rio de Janeiro, using remote sensing imagery}

\begin{abstract}
This study aimed to identify and to quantify the flooded area in the 2008/2009 summer period in the Norte Fluminense region, Rio de Janeiro state using remote sensing images. For this, Landsat-5 TM and CBERS-2B CCD images acquired before and after flooding occurrence were used. In these images, the Linear Spectral Mixture Model - LSMM was applied in order to highlight the areas occupied by water bodies. It was concluded that the water bodies in the region suffered an increment of 2.61 times corresponding to 99,000 ha of total area of water surface based on the comparison of the TM image acquired on July 26, 2007 (without flooding) with TM acquired on November 17, 2008 and with the CCD image of January 20, 2009 acquired after the rainy season in this region.
\end{abstract}

Keywords: Remote sensing; Linear Spectral Mixture Model; water resources; floodings. 
MENDONÇA, J. C.; FREITAS, R. M. ; SHIMABUKURO, Y. E.; MARQUES, V. S. Avaliação de eventos de inundação na Região Norte Fluminense, Rio de Janeiro, utilizando imagens de sensores remotos. Ambi-Agua, Taubaté, v. 7, n. 1, p. 255-267, 2012. (http://dx.doi.org/10.4136/ambi-agua.817)

\section{INTRODUÇÃO}

A Baixada Campista se localiza na região Norte Fluminense, Rio de Janeiro, às margens do trecho final do Rio Paraíba do Sul, abrangendo os municípios de Campos dos Goytacazes, São João da Barra, São Francisco de Itabapoana e Quissamã. Segundo Lamego (1955) essa região se caracteriza por uma vasta várzea originária de uma antiga baía que, após regressão marinha e ascensão continental, ocasionou uma planície de grande extensão.

O clima da região pela classificação de Köppen é considerado como tropical úmido (Aw), com verão chuvoso e inverno seco, sendo a normal climatológica da precipitação pluviométrica igual a 1.055,3 mm (Ramos et al., 2009). No entanto, a ocorrência de episódios extremos de precipitação tem gerado diversos problemas ambientais, dos quais se destacam cinco grandes inundações, somente na década de 2000.

Cataldi et al. (2010) citam que as principais teleconexões diretas entre o regime pluviométrico e hidrológico do sudeste da América do Sul são associadas às variações na Temperatura da Superfície do Mar (TSM) do Oceano Pacífico Equatorial e aos fenômenos do tipo El Niño-Oscilação Sul (ENOS), ficando as influências das anomalias na TSM do Oceano Atlântico Sul com papel secundário.

Gerólamo e Kayano (2010) citam que a TSM tem um papel preponderante na variabilidade climática interanual e interdecenal e que os padrões anômalos da circulação atmosférica associados às anomalias de TSM, hoje conhecidos como parte dos ciclos do fenômeno ENOS, conduzem a padrões climáticos anômalos em várias áreas do globo que se manifestam em diversas variáveis como a precipitação, temperatura do ar, pressão ao nível médio do mar, entre outras.

A disponibilidade atual de diversos dados de sensoriamento remoto, notadamente as imagens de satélites com diferentes resoluções espaciais, espectrais e temporais, muitas delas disponíveis gratuitamente na rede mundial de computadores, propiciou a crescente utilização desses dados nos trabalhos de monitoramento da superfície terrestre.

A técnica do Modelo Linear de Mistura Espectral (MLME) tem por base a análise subpixel e considera que a formação de um pixel é a mistura linear da resposta espectral das frações água/sombra, solo e vegetação em imagens multiespectrais (Shimabukuro e Smith, 1991). As imagens fração geradas realçam áreas de interesse para interpretação das imagens multiespectrais. Essa técnica vem sendo comumente utilizada em estudos da cobertura vegetal (Shimabukuro et al., 1998; Sabol et al., 2002; Silva et al., 2007; Shimabukuro et al., 2009; Lima et al., 2009; Moura et al., 2009). No entanto, apenas nos anos mais recentes, a técnica passou a ser empregada, com sucesso, em estudos hidrológicos por meio da análise da imagem fração água/sombra gerada pelo modelo.

Mendonça et al. (2007) avaliaram a aplicação do MLME com imagens MODIS/Terra e MODIS/Aqua, analisando o impacto de eventos de precipitações pluviométricas sobre a região Norte Fluminense, Rio de Janeiro, concluindo ser esta uma técnica eficiente e de baixo custo, podendo ser adotada operacionalmente como ferramenta de auxílio à política de gestão dos recursos hídricos.

Silva (2008) aplicou a técnica do MLME para mapear os diferentes tipos de água no rio Solimões e no lago de Coari utilizando imagens do TM Landsat-5 e concluiu que o MLME permitiu mapear as diferentes fases do ciclo hidrológico e os fluxos de água preta originários do lago de Coari no interior do rio Solimões.

Renó et al. (2009) avaliaram o desempenho de duas estratégias de classificação baseadas em regiões, com aplicação do MLME para o mapeamento das classes de água da bacia do alto Paraná.

Padovani et al. (2009) estudaram as inundações do Pantanal Mato-grossense para quantificar a dinâmica das inundações na área de influência do rio Paraguai e concluíram que 
MENDONÇA, J. C.; FREITAS, R. M. ; SHIMABUKURO, Y. E.; MARQUES, V. S. Avaliação de eventos de inundação na Região Norte Fluminense, Rio de Janeiro, utilizando imagens de sensores remotos. Ambi-Agua, Taubaté, v. 7, n. 1, p. 255-267, 2012. (http://dx.doi.org/10.4136/ambi-agua.817)

o emprego do MLME em imagens MODIS mostraram-se muito úteis no mapeamento e na caracterização da dinâmica das inundações do Pantanal, podendo ser usados para o monitoramento quantitativo das inundações desse bioma. Os mesmos autores citam ainda que os métodos convencionais de classificação de imagens limitam-se à classes qualitativas, porém, com o emprego do MLME é possível quantificar a proporção de determinado alvo de interesse e dessa forma, nas imagens fração água/sombra, cada pixel representa uma estimativa da proporção de água na superfície do terreno, sendo possível relacionar cada pixel da imagem com os dados de superfície e obter um mapa dessa relação.

Evans et al. (2010) utilizaram imagens multi-temporais de radar ALOS/PALSAR e RADARSAT-2 para mapear o uso e a cobertura da terra e a dinâmica das inundações do Panantal Matogrossense, concluindo que os mapas gerados são um recurso valioso para a definição de habitats necessários para conservar a biodiversidade do Pantanal e para mitigar os impactos do desenvolvimento humano na região.

Dessa forma, o presente trabalho teve por objetivo identificar e quantificar, com o uso de imagens de sensoriamento remoto, as áreas atingidas pelas inundações ocorridas no período do verão dos anos de 2008/2009 na região Norte Fluminense, Rio de Janeiro.

\section{MATERIAL E MÉTODOS}

\subsection{Caracterização da Área de Estudo}

A área objeto deste trabalho localiza-se às margens do trecho final do Rio Paraíba do Sul, abrangendo os municípios de Campos dos Goytacazes, São Francisco de Itabapoana, São João da Barra e Quissamã, todos na região norte do Estado do Rio de Janeiro (Figura 1). Segundo Lamego (1955), essa região caracteriza-se por uma vasta várzea originária de uma antiga baía que, após regressão marinha e ascensão continental, ocasionou uma planície de grande extensão onde é comum a ocorrência de solos com camadas argilosas, cuja distribuição é aleatória. Mendonça et al. (2007) citam que a explicação para a distribuição heterogênea dos solos na planície fluvial pode ser a história geológica da região, formada por aportes de sedimentos marinhos e fluviais da era Quaternária, na margem direita, e Terciária, na margem esquerda do trecho final do rio Paraíba do Sul.

Segundo a classificação climática de Köeppen, a região Norte Fluminense insere-se na classe Aw, isto é, tropical úmido, com verão chuvoso, inverno seco e temperatura do mês mais frio superior a $18{ }^{\circ} \mathrm{C}$. A temperatura média anual situa-se em torno de $24{ }^{\circ} \mathrm{C}$, sendo a amplitude térmica pequena e a normal climatológica da precipitação pluviométrica igual a 1.055,3 mm (Ramos et al., 2009).

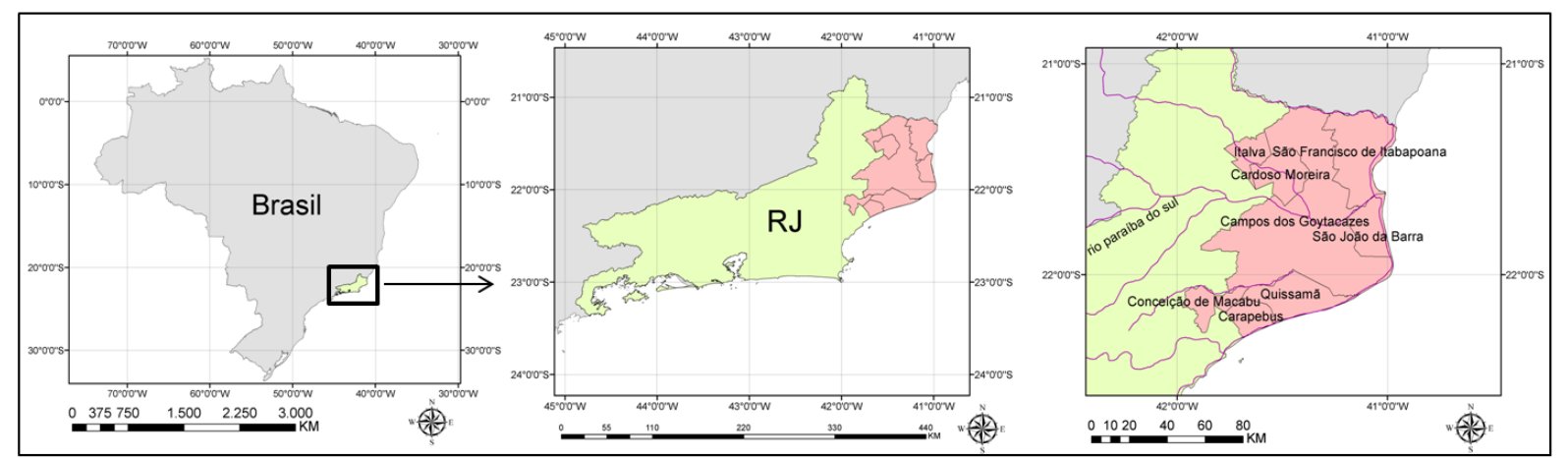

Figura 1. Localização da área de estudo em referência ao Estado do Rio de Janeiro e ao Brasil. 
MENDONÇA, J. C.; FREITAS, R. M. ; SHIMABUKURO, Y. E.; MARQUES, V. S. Avaliação de eventos de inundação na Região Norte Fluminense, Rio de Janeiro, utilizando imagens de sensores remotos. Ambi-Agua, Taubaté, v. 7, n. 1, p. 255-267, 2012. (http://dx.doi.org/10.4136/ambi-agua.817)

Na Figura 2 é apresentada a rede hidrográfica existente na área de estudo, com destaque para a lagoa Feia e a localização das estações meteorológicas onde foram coletados parte dos dados pluviométricos utilizados neste estudo.

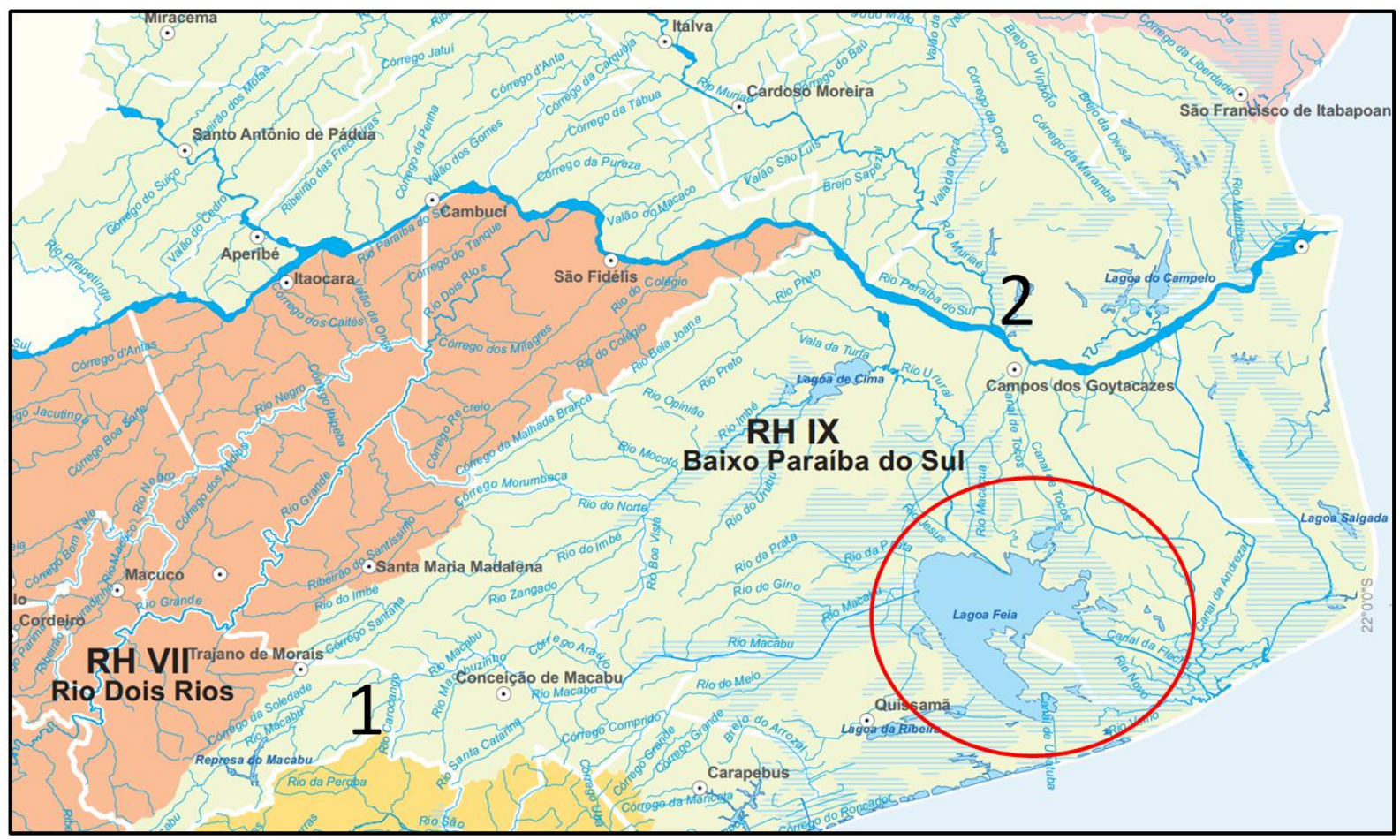

Figura 2. Rede hidrográfica existente na área de estudo. 1. Plataforma de Coleta de Dados do SIMERJ/CPTEC e 2. Estação do INMET.

Fonte: Adaptado de INEA (2008).

\subsection{Imagens de Sensores Remotos}

$\mathrm{Na}$ elaboração deste trabalho foram utilizadas imagens adquiridas pela câmera CCD CBERS-2B no dia 02/12/2008 referentes a órbita 146 e pontos 124 e 125 que possuem resolução espacial de $20 \mathrm{~m}$ x $20 \mathrm{~m}$ e imagens do sensor TM Landsat-5 adquiridas nos dias 26/07/2007 e 20/01/2009 referentes a órbita/ponto 216/75 cuja resolução espacial é de $30 \mathrm{~m} \mathrm{x}$ $30 \mathrm{~m}$, sendo todas essas imagens obtidas gratuitamente no site do Instituto Nacional de Pesquisas Espaciais - INPE. Os recortes utilizados envolveram a área compreendida pelas coordenadas geográficas $21^{\circ} 10^{\prime}$ e $22^{\circ} 25^{\prime}$ de latitude Sul e $40^{\circ} 45^{\prime}$ e $42^{\circ} 10^{\prime}$ de longitude Oeste.

Para as etapas de pré-processamento, recortes, aplicação do MLME e geração dos mapas temáticos foi utilizado o software Environment for Visualizing Images - ENVI, ver. 4.3.

\subsection{Dados Pluviométricos e Batimétricos}

Os dados pluviométricos foram coletados por uma estação meteorológica automática modelo Vaisalla, pertencente ao Instituto Nacional de Meteorologia - INMET, instalada no Colégio Estadual Agrícola Antônio Sarlo situada no município de Campos dos Goytacazes, RJ (Coordenadas $21^{\circ} 71,47^{\prime}$ de latitude Sul e $41^{\circ} 34,41^{\prime}$ de longitude Oeste; Altitude de 25 $\mathrm{m})$, na Plataforma de Coleta de Dados - PCD, da rede do Sistema de Meteorologia do Estado do Rio de Janeiro - SIMERJ/CPTEC, instalada no município de Santa Maria Madalena, RJ (Coordenadas $21^{\circ}$ 95' de latitude Sul e 42 ${ }^{\circ}$ 00' de longitude Oeste; Altitude de $615 \mathrm{~m}$ ) e na série de dados pluviométricos da Companhia Açucareira Paraíso (Coordenadas $21^{\circ} 53,88^{\prime}$ de latitude Sul e $41^{\circ} 17,28^{\prime}$ de longitude Oeste; Altitude de $8 \mathrm{~m}$ ). 
MENDONÇA, J. C.; FREITAS, R. M. ; SHIMABUKURO, Y. E.; MARQUES, V. S. Avaliação de eventos de inundação na Região Norte Fluminense, Rio de Janeiro, utilizando imagens de sensores remotos. Ambi-Agua, Taubaté, v. 7, n. 1, p. 255-267, 2012. (http://dx.doi.org/10.4136/ambi-agua.817)

Os dados batimétricos foram coletados na régua de monitoramento da lagoa Feia instalada pelo Instituto Estadual do Ambiente - INEA na localidade de Ponta Grossa dos Fidalgos, município de Campos dos Goytacazes, RJ (Coordenadas 21 $56^{\circ}$ de latitude Sul e $41^{\circ} 20^{\prime}$ de longitude Oeste; Altitude de $5 \mathrm{~m}$ ).

\subsection{Modelo Linear de Mistura Espectral (MLME)}

O MLME faz a suposição de que a resposta de um pixel em cada banda espectral é a combinação linear ponderada das respostas espectrais das componentes selecionadas. $\mathrm{O}$ fator de ponderação é dado pela fração da área do pixel ocupada pela respectiva componente (endmember). Para cada pixel individual, o modelo linear de mistura pode ser expresso por:

$$
R_{k}=\sum_{j=1}^{m} r_{j, k} f_{j}+v_{k}(k=1, \ldots, p)
$$

Em que, $R_{k}$ representa a resposta espectral de um pixel na banda espectral $k, r_{j, k}$ a resposta espectral da componente $j$ na banda espectral $k, f_{j}$ a fração da área total do pixel ocupada pela componente $j, m$ o numero de componentes, $v_{k}$ o valor do resíduo em (1) para a banda espectral $k$ e $p$ o número de bandas espectrais dos sensores remotos em consideração. As respostas espectrais $R_{k}$ e $r_{j, k}$ podem ser expressas em termos de refletância espectral, radiância espectral ou número digital. Neste estudo, optou-se por número digital, uma vez que o interesse é somente na classificação da imagem.

\subsection{Procedimento Metodológico}

Neste trabalho o MLME foi aplicado nas bandas espectrais dos sensores TM (b1-azul, b2-verde, b3-vermelho, b4-infravermelho próximo, b5-infravermelho médio e b7infravermelho médio) e CCD CBERS-2B (b1-azul, b2-verde, b3-vermelho e b4infravermelho próximo) utilizando três componentes, solo, água/sombra e vegetação. A fração solo ressalta as áreas de solo exposto, a fração vegetação se assemelha aos índices de vegetação ressaltando o vigor da vegetação, e a fração água/sombra ressalta bem os corpos d'água e valores com baixa refletância espectral. A seleção dos pixels puros (endmember) baseou-se na experiência do foto-intérprete. Foram selecionados pixels de vegetação uniforme e densa para a fração vegetação, solo exposto para a fração solo e água sem sedimentos para a fração água/sombra.

A imagem fração água/sombra gerada a partir do MLME foi utilizada para estimar a área total ocupada pelo espelho d`água da área de estudo. Para esse cálculo, após supervisão do foto-intérprete, considerou-se para fatiamento, o limiar de $70 \%$ da imagem fração água/sombra obtendo-se uma imagem binária de espelho d'água. Os valores contaminados por sombras de nuvens foram editados, a fim de se evitar confusão entre as classes, o que em alguns casos poderia gerar uma super-estimativa das áreas inundadas.

\section{RESULTADOS E DISCUSSÃO}

\subsection{Cronologia dos Eventos}

O período chuvoso na Região Norte Fluminense se iniciou em meados do mês de outubro/2008 estando à cota batimétrica da lagoa Feia em níveis controlados e relativamente baixos para o período. Em 01/11/2008 o nível da lagoa observado na localidade de Ponta Grossa dos Fidalgos era de 3,20 m e em 17/11/2008 de 3,25 m. Em Santa Maria Madalena, RJ, à montante da lagoa de Cima foi registrado no dia 15/11/2008 um evento de precipitação de $360,25 \mathrm{~mm}$ e entre as $21 \mathrm{~h}$ do dia $17 / 11$ e as $9 \mathrm{~h}$ do dia 18/11 foi registrado em Campos 
MENDONÇA, J. C.; FREITAS, R. M. ; SHIMABUKURO, Y. E.; MARQUES, V. S. Avaliação de eventos de inundação na Região Norte Fluminense, Rio de Janeiro, utilizando imagens de sensores remotos. Ambi-Agua, Taubaté, v. 7, n. 1, p. 255-267, 2012. (http://dx.doi.org/10.4136/ambi-agua.817)

dos Goytacazes, RJ, a ocorrência de 189,8 mm totais de chuvas. Esses eventos pluviométricos contribuíram para o transbordamento dos rios Macabú, Imbé e Preto, sendo esses dois últimos afluentes da lagoa de Cima e todos, afluentes da lagoa Feia.

De acordo com o Instituto Nacional de Meteorologia - INMET, a Normal Climatológica do mês de novembro, em Campos dos Goytacazes, RJ, é de 160,6 mm e a altura máxima de precipitação em 24 h, ocorreu no dia 20 de novembro do ano de 1972, no valor de 117,2 mm. No entanto os dados dessas Normais Climatológicas, por serem referentes ao período de 1961 a 1990, devem ser considerados apenas como valores de referência, pois ao deixar, nesse trabalho, uma lacuna de quase 20 anos de dados podem não representar a situação atual, o que em muito pode comprometer a avaliação de eventos climáticos extremos possivelmente relacionados com mudanças climáticas globais.

Na Figura 3 é apresentado o gráfico das médias mensais da precipitação pluviométrica ocorridas entre os meses de outubro a março dos anos de 2000 a 2009, bem como os totais acumulados nesses mesmos períodos.

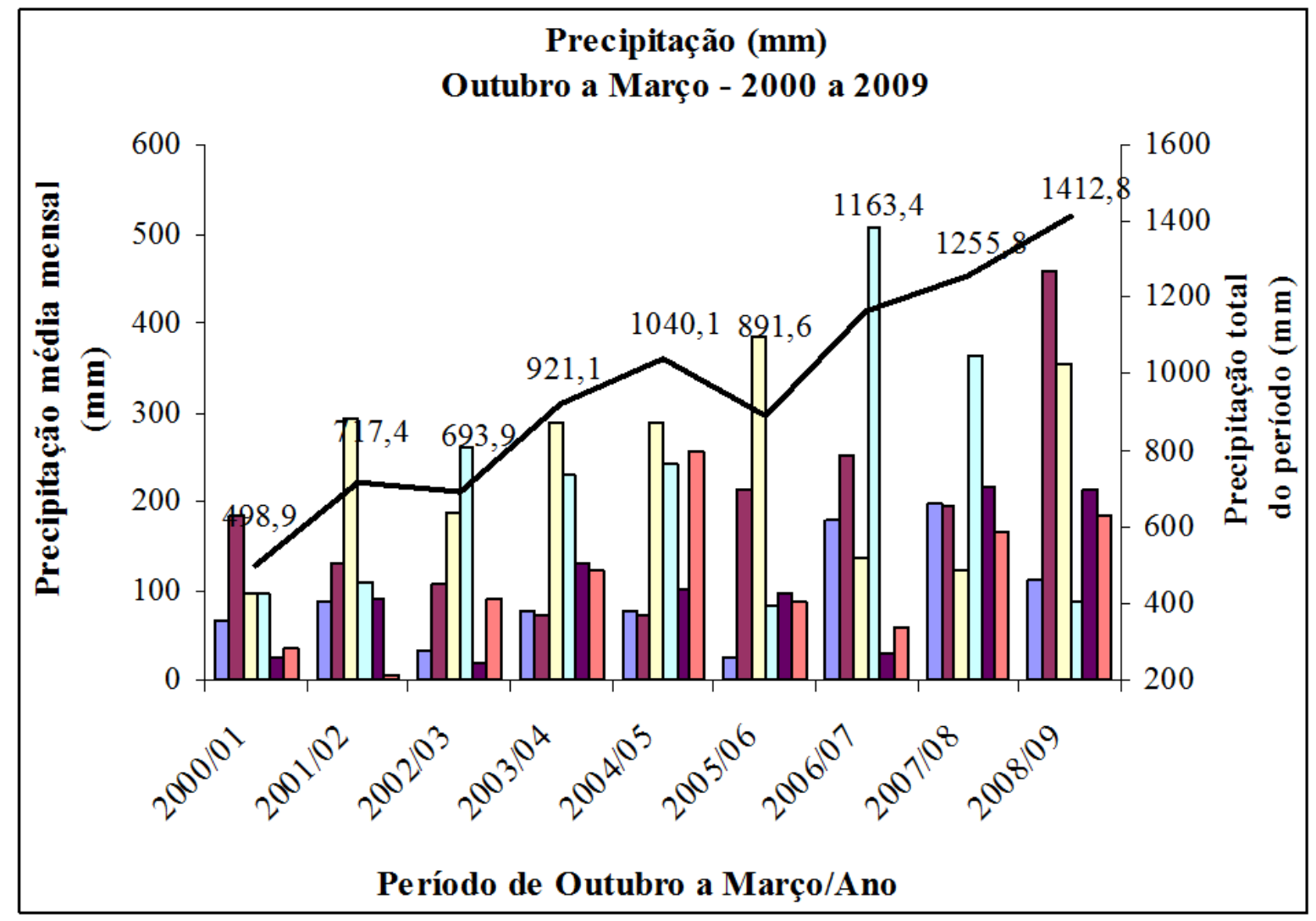

Figura 3. Gráfico das médias mensais da precipitação pluviométrica ocorridos entre os meses de outubro a março dos anos de 2000 a 2009, bem como os totais acumulados nesses períodos.

Fonte: Dados fornecidos por comunicação pessoal com a Companhia Açucareira Paraíso, Campos dos Goytacazes (2009).

Observando a Figura 3 pode-se perceber que os totais acumulados no período outubro a março sofreram um incremento progressivo nessa década de 2000, passando de pouco menos de $500 \mathrm{~mm}$ (2000/2001) para cerca de $1400 \mathrm{~mm}$ (2008/2009), sendo este incremento associado por Cataldi et al. (2010) às variações na Temperatura da Superfície do Mar (TSM) do Oceano Pacífico Equatorial e aos fenômenos ENOS. 
MENDONÇA, J. C.; FREITAS, R. M. ; SHIMABUKURO, Y. E.; MARQUES, V. S. Avaliação de eventos de inundação na Região Norte Fluminense, Rio de Janeiro, utilizando imagens de sensores remotos. Ambi-Agua, Taubaté, v. 7, n. 1, p. 255-267, 2012. (http://dx.doi.org/10.4136/ambi-agua.817)

Na Figura 4 é apresentado o gráfico da evolução da cota da lagoa Feia, medida na localidade de Ponta Grossa dos Fidalgos e dos eventos de precipitação durante o período de 01/11/2008 a 30/01/2009 medidos em Campos dos Goytacazes, RJ.

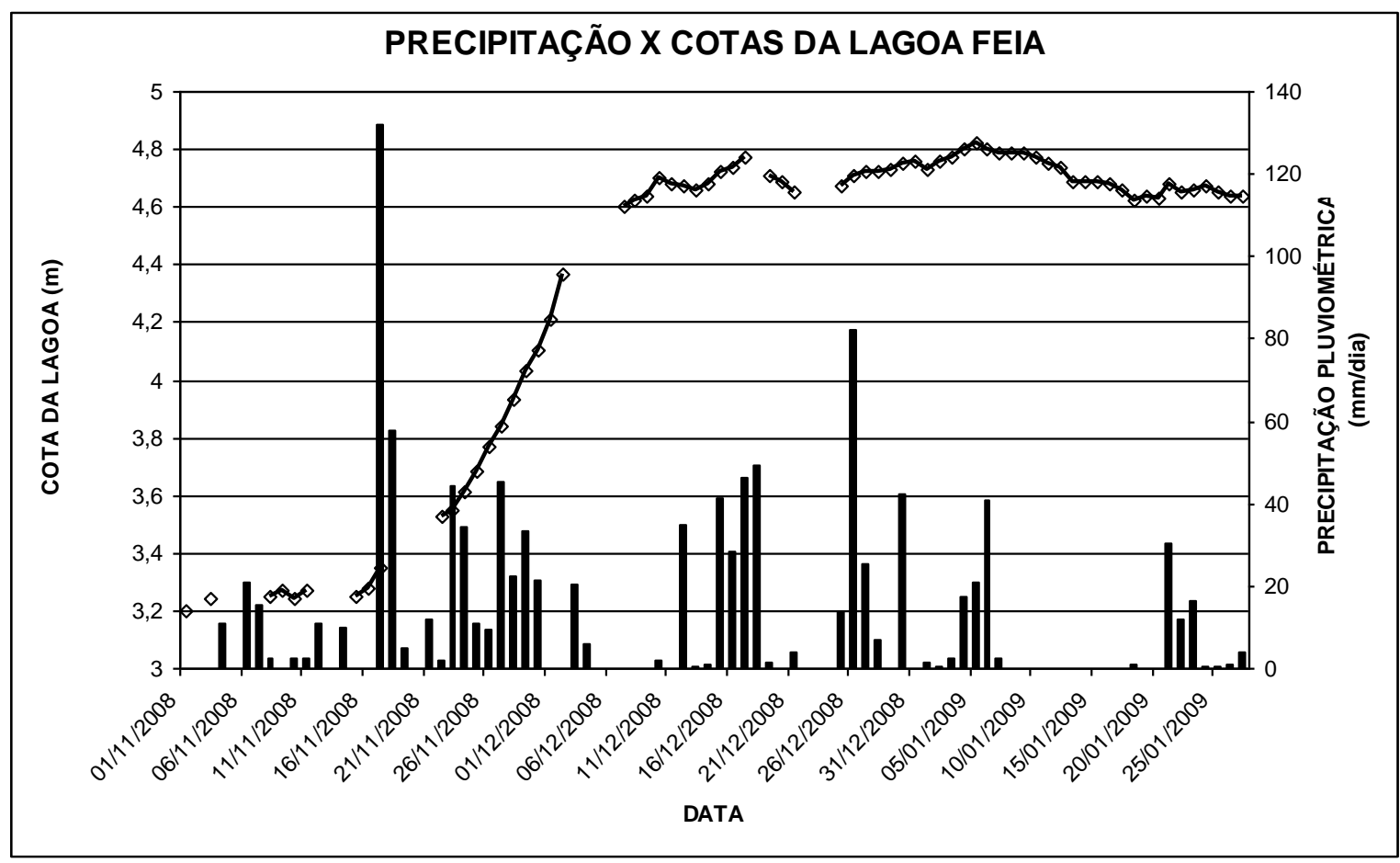

Figura 4. Gráfico da evolução da cota da lagoa Feia e dos eventos de precipitação durante o período de 01/11/2008 a 30/01/2009.

Observando a Figura 4 pode-se perceber que após as fortes chuvas ocorridas à montante da bacia da lagoa de Cima, a cota da lagoa Feia passou a se elevar bruscamente, passando da cota de 3,25 m em 17/11/2008 para 4,10 m em 02/12/2008, representando uma elevação de $0,85 \mathrm{~m}$ em apenas 15 dias.

\subsection{Analise das Imagens CCD CBERS-2B e TM Landsat-5}

Nesta análise aplicou-se a técnica do MLME para avaliar e quantificar a mancha de inundação da área estudada. Como parâmetro inicial utilizou-se uma cena do sensor TM Landsat-5, imageada em 26/07/2007, buscando representar a área do espelho d’água da região em estado de normalidade, ou seja, fora do período chuvoso.

Na Figura 5 são apresentadas as composições coloridas (R5 G4 B3) do TM adquirida no dia 26/07/2007 e das imagens fração derivadas do MLME (Água/sombra Solo Vegetação), evidenciando as áreas ocupadas pelos espelhos d'água.

Na Figura 5 pode-se perceber o comportamento do espelho d'água da região, devidamente em seus limites físicos. A coloração mais avermelhada na Figura 5B destaca as áreas da fração solo gerada pelo MLME. Essa evidência na fração solo se justifica por ser um período de baixa precipitação pluviométrica (inverno seco), coincidindo com a colheita da cana-deaçúcar, principal cultura agrícola local. A área dos corpos d’água extraída da fração água/sombra nesta mesma Figura 5B foi quantificada pela ferramenta "Contagem de pixels Estatística de Polígonos", do software ENVI ver. 4.3, em 27.400 ha.

Na Figura 6 é apresentada a imagem da fração água/sombra gerada pelo MLME aplicado sobre a imagem CCD CBERS-2B adquirida em 02/12/2008 evidenciando a mancha de inundação e fotografias aéreas de alguns trechos dessa área inundada. 
MENDONÇA, J. C.; FREITAS, R. M. ; SHIMABUKURO, Y. E.; MARQUES, V. S. Avaliação de eventos de inundação na Região Norte Fluminense, Rio de Janeiro, utilizando imagens de sensores remotos. Ambi-Agua, Taubaté, v. 7, n. 1, p. 255-267, 2012. (http://dx.doi.org/10.4136/ambi-agua.817)

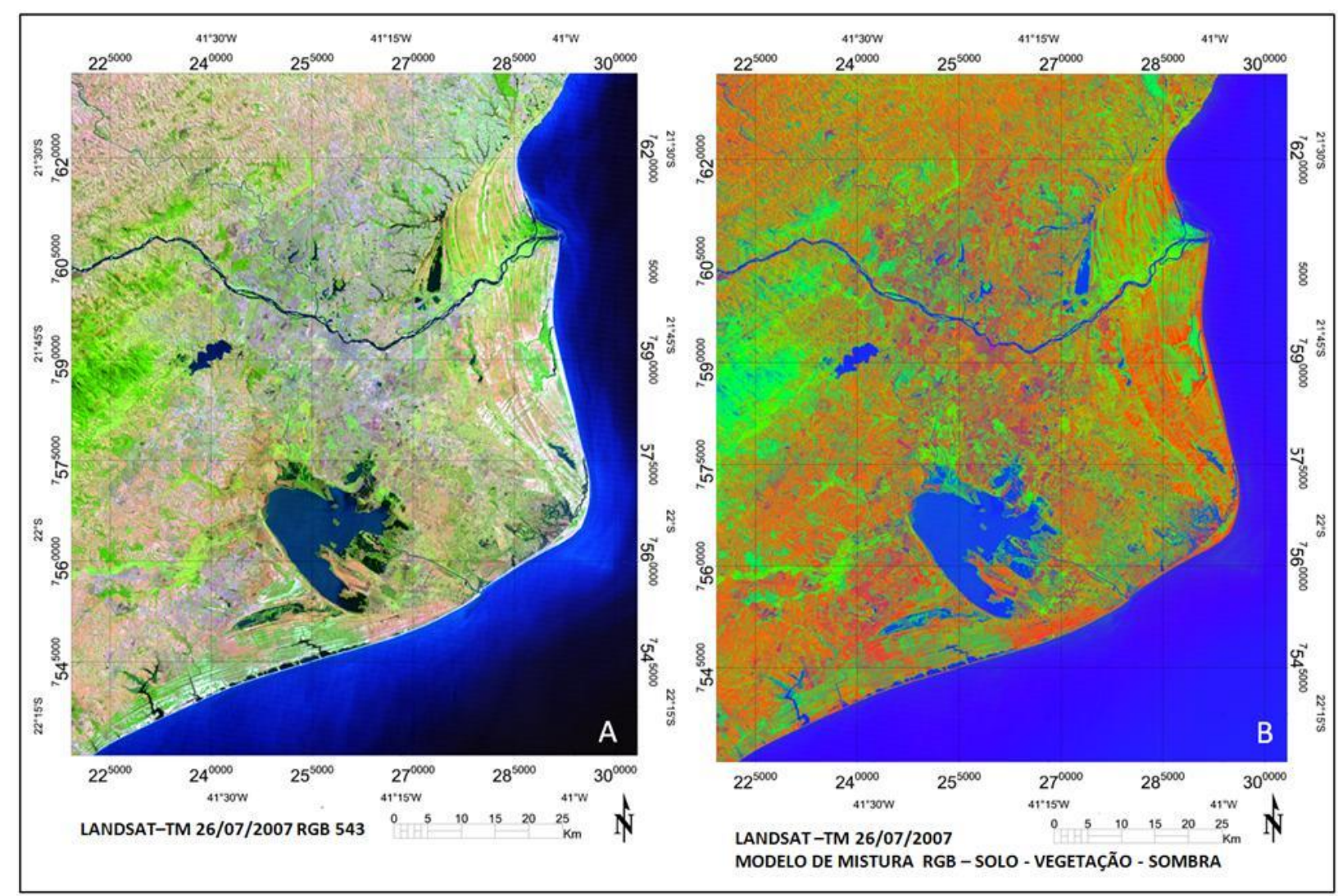

Figura 5. Imagem TM de 26/07/2007 da Região Norte Fluminense, RJ. Composição RGB 543 e composição colorida das frações RGB Solo-Vegetação-Água/Sombra.

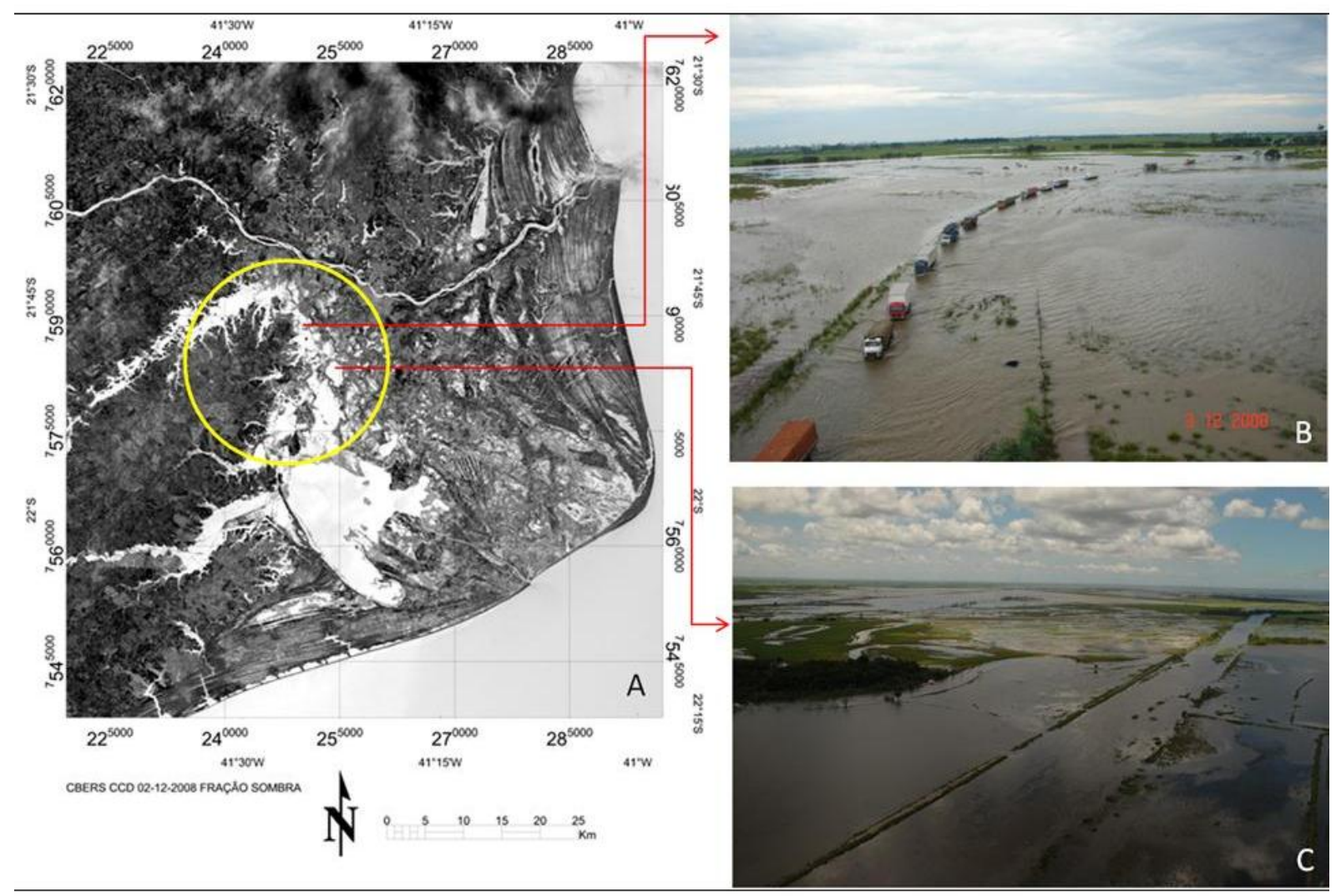

Figura 6. Imagem da fração água/sombra gerada pelo MLME aplicado sobre a imagem CCD CBERS2B (A), e fotografias aéreas de alguns trechos dessas áreas inundadas (B e C). 
MENDONÇA, J. C.; FREITAS, R. M. ; SHIMABUKURO, Y. E.; MARQUES, V. S. Avaliação de eventos de inundação na Região Norte Fluminense, Rio de Janeiro, utilizando imagens de sensores remotos. Ambi-Agua, Taubaté, v. 7, n. 1, p. 255-267, 2012. (http://dx.doi.org/10.4136/ambi-agua.817)

A região de maior magnitude de escoamento superficial (runoff) no Estado do Rio de Janeiro, desvia do leito do Rio Paraíba do Sul, entre as cidades de Campos dos Goytacazes e São Fidelis, em direção a Lagoa Feia (Costa et al., 2009), saindo das Escarpas e Reversos da Serra do Mar, Colinas e Maciços Costeiros para a Planície Costeira (Bergallo et al., 2009). Analisando a Figura 6 pode-se perceber que, em 02/12/2008 a mancha de inundação se concentra na direção deste fluxo, motivo pelo qual a cidade de Campos dos Goytacazes não sofreu maiores impactos decorrentes dos eventos extremos de precipitação. As sub-bacias mais impactadas foram as dos rios Imbé, Ururaí, Prata e Macabú.

Na Figura 7 é apresentada a imagem da fração água/sombra gerada pelo MLME aplicado sobre a imagem TM Landsat-5 de 20/01/2009 evidenciando a mancha de inundação e fotografias aéreas de alguns trechos da área inundada no entorno da lagoa Feia.

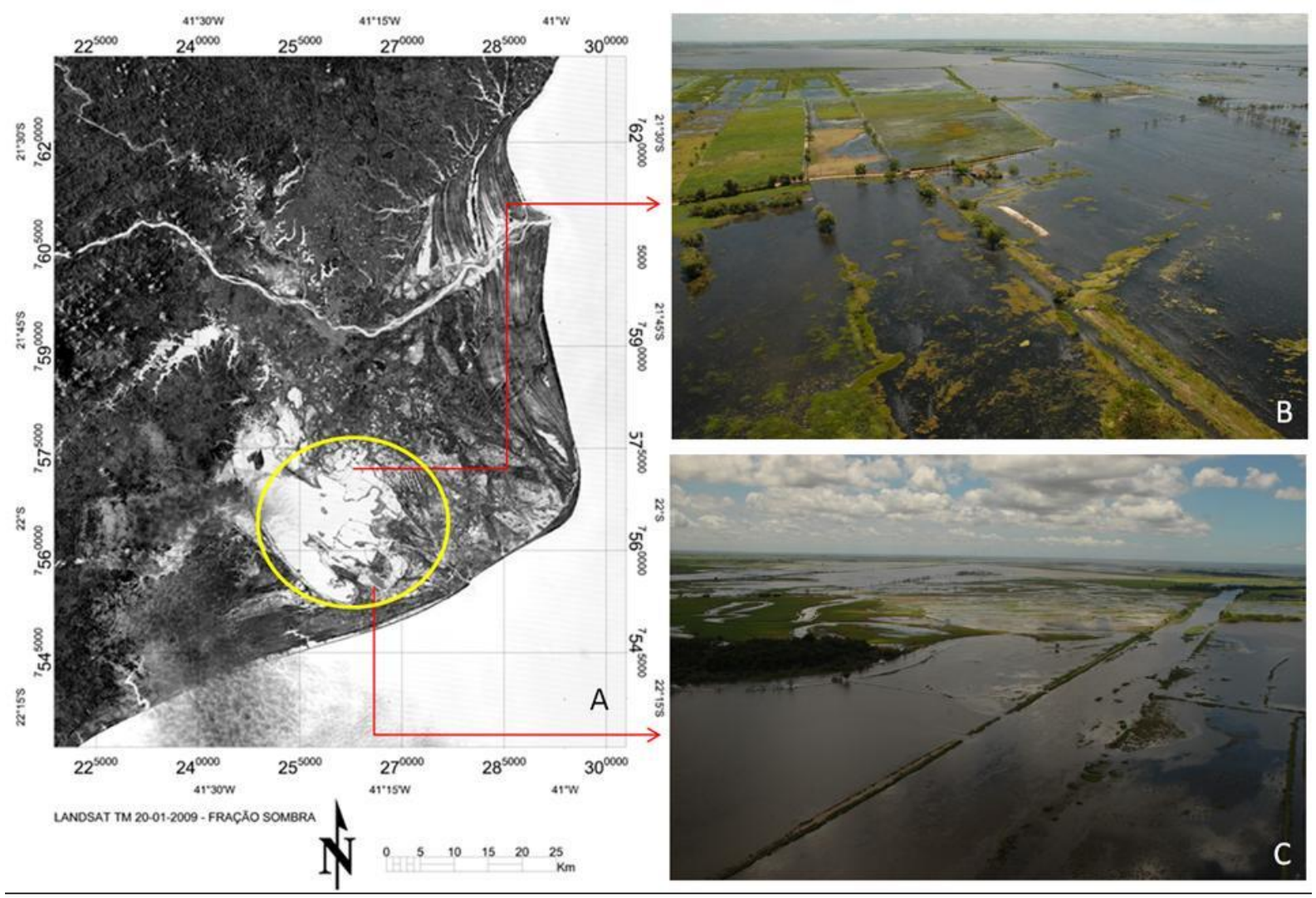

Figura 7. Imagem da fração água/sombra gerada pelo MLME aplicado sobre a imagem TM Landsat-5 de 20/01/2009 evidenciando a mancha de inundação em (A) e fotografias aéreas de alguns trechos das áreas inundadas (B e C).

Na análise da Figura 7 deve-se destacar a contaminação por nuvens sobre a sub-bacia do rio Macabú e lagoa da Ribeira (trecho sul da imagem). Mas a região leste da lagoa Feia se encontra devidamente evidenciada, sem contaminação de nuvens e sendo assim possível se fazer uma análise mais detalhada e perceber que a região a leste da lagoa Feia se encontra fortemente impactada pelo deslocamento da mancha de inundação. Sendo a Baixada Campista uma região muito ampla abrangendo todo o litoral Norte Fluminense, desde São Francisco de Itabapoana a Conceição de Macabu, a inundação a leste da Lagoa Feia representa apenas uma parte desta região, que foi alagada pelo fluxo proveniente da acomodação e distribuição do volume d'água à montante do escoamento e acumulo anterior, concordando com as afirmações de Costa et al. (2009) e Bergallo et al. (2009) quanto ao regime do escoamento superficial (runoff) para esta região do estado do Rio de Janeiro. 
MENDONÇA, J. C.; FREITAS, R. M. ; SHIMABUKURO, Y. E.; MARQUES, V. S. Avaliação de eventos de inundação na Região Norte Fluminense, Rio de Janeiro, utilizando imagens de sensores remotos. Ambi-Agua, Taubaté, v. 7, n. 1, p. 255-267, 2012. (http://dx.doi.org/10.4136/ambi-agua.817)

\section{3. Área Total Atingida Pelas Inundações}

Com a sobreposição das áreas da fração água/sombra obtidas pela aplicação da técnica do MLME extraídas das imagens CCD CBERS-2B de 02/12/08 e TM Landsat-5 de 20/01/09 foi possível estimar a área total atingida pelos eventos das inundações ocorridas neste período.

Na Figura 8 são apresentadas os espelhos d'águas extraídos das imagens TM Landsat-5 e CCD CBERS-2B que permitem a visualização e a quantificação da evolução da mancha de inundação sobre a região em análise, bem como as áreas que permaneceram inundadas por períodos mais prolongados.

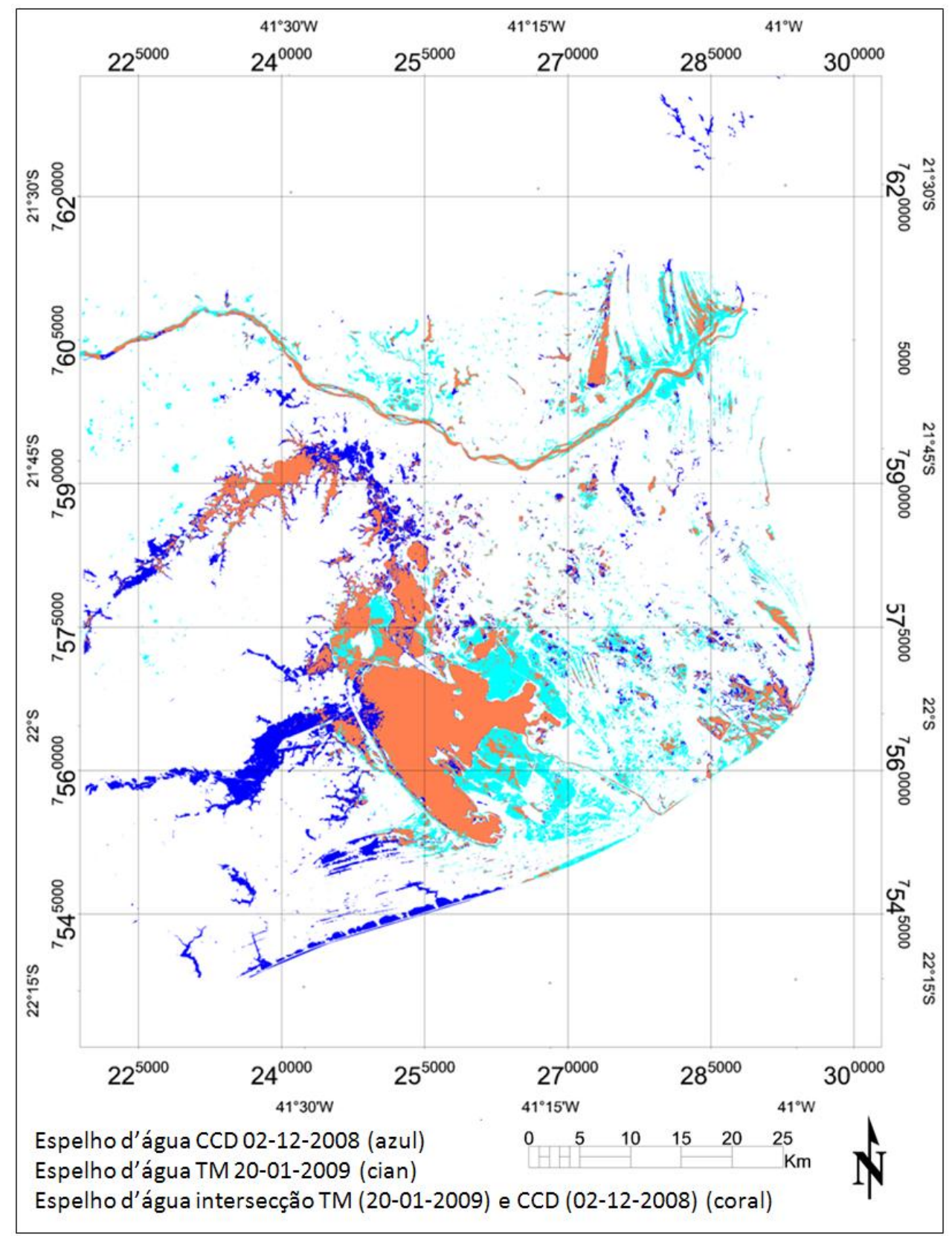

Figura 8. Espelho d’água da imagem CCD CBERS - 2B de 02/12/2008 (azul), da imagem TM Landsat-5 de 20/01/2009 (cian) e espelho d’água em comum entre às duas imagens (coral).

Observando a Figura 8 é possível verificar as áreas sobrepostas entre as imagens CCD CBERS-2B de 02/12/2008 e TM Landsat-5 de 20/01/2009 (coral) evidenciando as áreas do espelho d'água comum às duas imagens. Essas áreas em comum, com exceção do espelho 
MENDONÇA, J. C.; FREITAS, R. M. ; SHIMABUKURO, Y. E.; MARQUES, V. S. Avaliação de eventos de inundação na Região Norte Fluminense, Rio de Janeiro, utilizando imagens de sensores remotos. Ambi-Agua, Taubaté, v. 7, n. 1, p. 255-267, 2012. (http://dx.doi.org/10.4136/ambi-agua.817)

d’água da própria Lagoa Feia e da Lagoa de Cima (Figura 5), representam as áreas que permaneceram alagadas por um período mais prolongado que os demais, mesmo após o deslocamento e acomodação do escoamento para a região leste da área estudada (Figura 7). $\mathrm{O}$ total da área do espelho d'água existente na Figura 8 (azul + cian + coral) foi quantificada pela ferramenta "Contagem de pixels - Estatística de Polígonos", do software ENVI ver. 4.3, em 99.000 ha. Dessa maneira, pode-se observar que o espelho d'água da região sofreu um incremento de 2,61 vezes impactando uma área de 71.600 ha, quando comparada com o espelho d'água extraída da imagem TM de referência (26/07/2007).

\section{CONCLUSÃO}

Os mapas do espelho d’água gerados a partir das imagens fração água/sombra derivadas do MLME apresentam a evolução do deslocamento da mancha de inundação. Esses mapas são importantes para a identificação das áreas atingidas, podendo ser utilizados na avaliação sócio-econômica dos prejuízos ocorridos e nas atividades mitigatórias visando o controle de enchentes na região.

Com base na imagem do dia 26/07/2007 (período sem chuvas) e nas imagens dos dias 02/12/2008 e 20/01/2009, pode-se concluir que o espelho d'água da região sofreu um incremento de 2,61 vezes impactando uma área de 71.600 ha.

A metodologia adotada utilizando imagens TM Landsat-5 e CCD CBERS-2B, disponibilizadas gratuitamente na internet se mostrou eficiente para auxiliar a gestão dos recursos hídricos na região Norte Fluminense, Rio de Janeiro.

\section{REFERÊNCIAS}

BERGALlO, H. G.; FIDALGO, E. C.; ROCHA, C. F. D. et al. Estratégias e ações para a conservação da biodiversidade no Estado do Rio de Janeiro e outros. Rio de Janeiro: Instituto Biomas, 2009. 344 p.

CATALDI, M.; ASSAD, L. P. de F.; TORRES JÚNIOR, A. R.; ALVES, J. L. D. Estudo da influência das anomalias da TSM do Atlântico Sul extratropical na região da confluência Brasil Malvinas no regime hidrometeorológico de verão do sul e sudeste do Brasil. Revista Brasileira de Meteorologia, São José dos Campos, v.25, n.4, p. 513$524,2010$.

COSTA, T. C. C; FIDALGO, E. C. C.; NAIME, E. J.; GUIMARÃES, S. P.; ZARONI, M. J.; UZEDA, M. C. Vulnerabilidade de sub-bacias hidrográficas do estado do Rio de Janeiro por meio da equação universal da perda de solo e da integração de parâmetros morfométricos, topográficos, hidrológicos e de uso/cobertura da terra no estado do Rio de Janeiro, Brasil. Revista Ambiente \& Água, Taubaté. v. 4. n. 1. p. 93-116, 2009.

EVANS, T.; COSTA, M. P. F. ; TELMER, K.; SILVA, T. S. F. Using ALOS/PALSAR and RADARSAT-2 to map land cover and seasonal inundation in the Brazilian Pantanal. IEEE J-STARS, Piscataway, v. 3, p. 560-575, 2010.

GERÓLAMO, R. O. P.; KAYANO, M. T. Variações do ciclo anual da temperatura da superfície do mar no Pacífico Tropical. Revista Brasileira de Meteorologia, São José dos Campos, v. 25, n. 2, p. 237-245, 2010. 
MENDONÇA, J. C.; FREITAS, R. M. ; SHIMABUKURO, Y. E.; MARQUES, V. S. Avaliação de eventos de inundação na Região Norte Fluminense, Rio de Janeiro, utilizando imagens de sensores remotos. Ambi-Agua, Taubaté, v. 7, n. 1, p. 255-267, 2012. (http://dx.doi.org/10.4136/ambi-agua.817)

INSTITUTO ESTADUAL DO AMBIENTE - INEA (Rio de Janeiro). Divisão de Outorga. Núcleo de Geotecnologias. Mapa das regiões hidrográficas do Estado do Rio de Janeiro. Rio de Janeiro, 2008. Disponível em: <http://www.inea.rj.gov.br/ recursos/re_hidrograf.asp>. Acesso em: 10 mar. 2009.

LAMEGO, A. R. Geologia das quadrículas de Campos, São Tomé, Lagoa Feia e Xexé. Boletim 154. Rio de Janeiro: DNPM, 1955. 60 p.

LIMA, A.; SHIMABUKURO, Y. E.; ADAMI, M.; FREITAS, R. M.; ARAGÃO, L. E. O. C.; FORMAGGIO, A. R. et al. Mapeamento de cicatrizes de queimadas na amazônia brasileira a partir da aplicação do Modelo Linear de Mistura Espectral em imagens do sensor MODIS. In: SIMPÓSIO BRASILEIRO DE SENSORIAMENTO REMOTO SBSR, 14., 25 - 30 abril 2009, Natal. Proceedings... São José dos Campos: INPE, 2009. p. 5925-5932. 1 CD-ROM.

MENDONÇA, J. C.; FREITAS, R. M.; SOUSA, E. F. Avaliação temporal dos eventos de inundação da Baixada Campista, Região Norte Fluminense, RJ, pelo uso de imagens digitais orbitais do sensor MODIS. Revista Brasileira de Cartografia, Rio de Janeiro, v. 59, n. 03, p. 249/4-253, 2007.

MOURA, Y. M.; ARAI, E.; SHIMABUKURO, Y. E.; SANTOS, J. R.; FISCH, G. F.; NOVAES JUNIOR, R. A. et al. Aplicação do MLME em imagens MODIS para o estudo do comportamento de fitofisionomias da Floresta Atlântica e sua relação com a variabilidade pluviométrica. In: SIMPÓSIO BRASILEIRO DE SENSORIAMENTO REMOTO -SBSR, 14., 25 - 30 abril 2009, Natal. Proceedings... São José dos Campos: INPE, 2009. p. 2847-2854. 1 CD-ROM.

PADOVANI, C. R.; VETTORAZZI, C. A.; SHIMABUKURO, Y. E.; ADAMI, M.; FREITAS, R. M. Estudo das inundações do Pantanal a partir de imagens MODIS. In: SIMPÓSIO BRASILEIRO DE SENSORIAMENTO REMOTO - SBSR, 14., 25 - 30 abril 2009, Natal. Proceedings... São José dos Campos: INPE, 2009. p. 4805-4812. 1 CD-ROM.

RAMOS, A. M.; SANTOS, L. A. R.; FONTES, L. T. G. (Org.). Normais climatológicas do Brasil 1961-1990. Brasília, DF: INMET, 2009. 465 p.

RENÓ, V. F.; MORAES, L. E. S.; SAITO, E. A.; NASCIMENTO, R. F. F.; LOBO, F. L. SAMIZAVA, T. M. et al. Caracterização espectral das águas da Planície do Rio Paraná a partir de imagens Landsat TM. In: SIMPÓSIO BRASILEIRO DE SENSORIAMENTO REMOTO - SBSR, 14., 25 - 30 abril 2009, Natal. Proceedings... São José dos Campos: INPE, 2009. p. 4821-4828. 1 CD-ROM.

SABOL, D. E.; GILlESPIE, A. R.; ADAMS, J. B.; SMITH, M. O.; TUCKER, C. J. Structural stage in Pacific Northwest estimated using simple mixing models of multispectral images. Remote Sensing of Enviroment, v. 80, n. 1, p. 1-16, 2002. http://dx.doi.org/10.1016/S0034-4257(01)00245-0

SILVA, T. S. F.; FREITAS, R. M.; NOVO, E. M. L. M. Monitoramento de áreas alagáveis. In: BERNARDO F. T.; RUDORFF, B.; SHIMABUKURO, Y. E.; CEBALLOS, J. C. (Org.). O sensor Modis e suas aplicações ambientais no Brasil. 1. ed. São José dos Campos: Parêntese, 2007. v. 1. p. 255-263. 
MENDONÇA, J. C.; FREITAS, R. M. ; SHIMABUKURO, Y. E.; MARQUES, V. S. Avaliação de eventos de inundação na Região Norte Fluminense, Rio de Janeiro, utilizando imagens de sensores remotos. Ambi-Agua, Taubaté, v. 7, n. 1, p. 255-267, 2012. (http://dx.doi.org/10.4136/ambi-agua.817)

SILVA, W. C. S. Aplicação da técnica de Modelo Linear de Mistura Espectral (MLME) para o mapeamento de diferentes tipos de água no rio Solimões e no lago de Coari utilizando imagens Landsat-TM. 2008. 109f. Dissertação (Mestrado em Engenharia Civil) - Universidade Federal do Rio de Janeiro, Rio de Janeiro, 2008.

SHIMABUKURO, Y. E.; BATISTA, G. T.; MELLO, E. M. K.; MOREIRA, J.C.; DUARTE, V. Using shade fraction image segmentation to evaluate deforestation in Landsat Thematic Mapper images of the Amazon Region. International Journal of Remote Sensing, London, v. 19, n. 3, p. 535-541, 1998. http://dx.doi.org/10.1080/014311698216152

SHIMABUKURO, Y. E.; SMITH, J. A. The least-squares mixing models to generate fraction images derived from remote sensing multispectral data. IEEE Transactions on Geoscience and Remote Sensing, Piscataway, v. 29, n. 1, p. 16-20, 1991.

SHIMABUKURO, Y. E.; DUARTE, V.; ARAI, E.; FREITAS， R. M.; LIMA, A.; VALERIANO, D. M. et al. Fraction images derived from Terra MODIS data for mapping burnt areas in Brazilian Amazonia. International Journal of Remote Sensing, London, v. 30, n. 6, p. 1537-1546, 2009. http://dx.doi.org/10.1080/01431160802509058 